OPEN ACCESS

Edited by:

Christi Underwood Edge,

Northern Michigan University,

United States

Reviewed by: Sabine Glock

University of Wuppertal, Germany Balwant Singh,

Partap College of Education, India

${ }^{*}$ Correspondence: Nicole Zaruba nicole.zaruba@uni-potsdam.de

Specialty section:

This article was submitted to

Teacher Education,

a section of the journal

Frontiers in Education

Received: 19 October 2020 Accepted: 04 February 2021

Published: 23 April 2021

Citation:

Zaruba N, Westphal A, Gutmann Fand Vock M (2021) Preservice Teachers' Implicit and Explicit Attitudes Towards

Teaching and Learning.

Front. Educ. 6:619098.

doi: 10.3389/feduc.2021.619098

\section{Preservice Teachers' Implicit and Explicit Attitudes Towards Teaching and Learning}

\author{
Nicole Zaruba ${ }^{1 *}$, Andrea Westphal ${ }^{1}$, Franziska Gutmann ${ }^{2}$ and Miriam Vock ${ }^{1}$ \\ ${ }^{1}$ Department of Education, University of Potsdam, Potsdam, Germany, ${ }^{2}$ Department of Sport and Health Sciences, University of \\ Potsdam, Potsdam, Germany
}

When it comes to teacher attitudes towards teaching and learning, research relies heavily on explicit measures (e.g., questionnaires). These attitudes are generally conceptualized as constructivist and transmissive views on teaching and learning with constructivism often considered to be more desirable. In explicit measures, this can have drawbacks like socially desirable responding. It is for this reason that, in this study, we investigated implicit attitudes as well as explicit attitudes towards constructivism and transmission. $N=100$ preservice teachers worked on a questionnaire and two Single-Target Implicit Association Tests (ST-IAT constructivism and ST-IAT transmission) before $\left(\mathrm{T}_{1}\right)$ and after $\left(\mathrm{T}_{2}\right)$ a single master's semester. One group $(n=50)$ did student teaching while a second group $(n=50)$ took master's courses. We evaluated preservice teachers' views on teaching at the end of their masters' studies. Participants agreed with transmission and constructivism $\left(T_{1}\right)$ on both an explicit and implicit level. Implicit measures seem to exceed explicit measures in differentially assessing constructivist and transmissive views on teaching and learning. After student teaching $\left(T_{2}\right)$, there was no overall effect of attitude development but changes in rank indicate that participants' implicit attitudes towards constructivism and transmission developed differently for each individual.

\section{Keywords: preservice teacher, implicit attitude, student teaching, attitude, explicit attitude}

\section{INTRODUCTION}

When it comes to the question of what makes a good teacher, theory and research agree that it is more than just teachers' knowledge of pedagogical content. A teacher's attitudes are an important facet of their professional competence (Baumert and Kunter, 2013) and thus play a decisive role in teacher education (Fives and Buehl, 2012). From the beginning of a teacher's career, attitudes can influence their interpretation of classroom situations (Gregoire, 2003), the quality of their instruction (Voss et al., 2013), and potentially the achievement of their students (Staub and Stern, 2002; but see also Leuchter et al., 2006).

Fostering those attitudes that may be beneficial for teachers' instructional quality at an early stage should, therefore, be an essential goal of teacher education (Levin, 2015). Not least because attitudes, at the beginning of a teacher's career, appear to become more malleable through a combination of experience and reflection (Fives and Buehl, 2012). Learning opportunities that encompass both experience and reflection are an increasingly common element of a teacher's professional preparation, particularly during student teaching in preservice training programs (Zeichner, 2012; Rothland and Boecker, 2015). 
Many studies indicate that preservice teachers enter teacher training programs with deeply held, generally transmissive views on teaching (see Richardson, 2003 for a review). There are however, ambiguous results when it comes to which attitudes preservice teachers hold near the end of their teacher training (Fives et al., 2015) and the potential development of attitudes during experience-focused learning, which takes place, for instance, during student teaching (Fives and Buehl, 2012). This ambiguity can be explained by a number of factors, including challenges in assessing attitudes, which include social desirability bias (Nosek, 2007).

Social desirability is usually a relevant factor in assessing explicit, i.e. self-reported, attitudes. And yet, research on attitudes relies heavily on self-report measures (Gawronski and Bodenhausen, 2006; Bluemke and Friese, 2008), especially when it comes to attitudes towards teaching and learning (Fives et al., 2015). Assessment strategies that try to overcome this weakness aim to take implicit attitudes into account (e.g., Greenwald et al., 1998; Preckel et al., 2015) and there are a number of measures designed to capture implicit attitudes. The most widely used method is the Implicit Association Test (IAT), a computerized classification task that measures reaction times. In our study, we used a special form of the IAT, a Single-Target-IAT (ST-IAT) (Bluemke and Friese, 2008), as well as a questionnaire to assess explicit and implicit attitudes of preservice teachers near the end of their teacher training. In a pre-post design, we also investigated the potential development of the preservice teachers' explicit and implicit attitudes on teaching and learning during a semester of student teaching.

\section{THEORETICAL BACKGROUND}

\section{Preservice Teachers' Attitudes \\ Preservice Teachers' Attitudes Towards Teaching and Learning}

Attitudes are defined as a degree of preference for an object or situation (Rokeach, 1968; Pajares, 1992; Skott, 2015). In the school context, teachers may exhibit specific attitudes towards teaching and learning (e.g., Baumert and Kunter, 2013). When, for example, a math teacher has a positive attitude towards direct instruction, they may prefer to teach new topics using direct instruction instead of choosing some form of discovery learning. In the field of teacher education research and educational sciences, however, there is a lack of conceptual clarity when it comes to precisely defining what we mean by "attitudes." They are rarely differentiated from beliefs or subjective theories (Pajares, 1992) and are often used interchangeably. When it comes to research on teacher attitudes, conceptual clarity is often demanded, but constructs are usually not defined consistently "within and across fields" (Fives and Buehl, 2012, p. 473).

We have chosen to use the term attitude in this paper as we are dealing with preservice teachers' evaluations of two attitude objects: constructivist and transmissive views on teaching and learning. These attitude objects include value-laden normative elements (Terhart, 2003) as a constructivist view of teaching is often considered to be more desirable than a transmissive view on teaching (Mayer, 2004; Juvova et al., 2015). It is plausible to assume that these attitude objects might evoke "evaluative responses of some degree of favorability or unfavorability" (Eagly and Chaiken, 1998, p. 269). As such, our definition of attitudes follows Eagly and Chaiken's (1998) rather broad attitude model, which includes affective (emotions) as well as cognitive components (thoughts or cognitions) that other authors have used to define teachers' beliefs (Fives and Buehl, 2012; Gregoire Gill and Hardin, 2015; Skott, 2015). It should be noted that Eagly and Chaiken's (1998) definition of attitude also encompasses a behavioral component, which is not part of our study.

Teachers can have attitudes towards any element of teaching, for instance specific teaching methods of a subject like science (Chen et al., 2015) and they can also have more general attitudes towards teaching and learning (Fives et al., 2015). In our study, we focus on these more general attitudes for two reasons. Firstly, evidence suggests that the attitudes held by preservice teachers might be more general and naïe than those of experienced teachers (Duffin et al., 2012). Secondly, investigating general attitudes allows for study results that are applicable to all preservice teachers, regardless of their subject affiliation (Fives et al., 2015).

When it comes to general teacher attitudes towards teaching and learning, most empirical studies contrast a constructivist view of teaching and learning to a transmissive perspective (e.g., Voss et al., 2013; Decker et al., 2015; see also Fives et al., 2015 for a review). A constructivist view draws on constructivist learning theories (Voss et al., 2013), with learning considered to be an individual process that requires the active construction of knowledge; existing knowledge and preconceptions are seen to play a decisive role in the individual's learning process (Fives et al., 2015). A transmissive perspective on teaching and learning, on the other hand, envisions students as the recipients of a clearly defined canon of knowledge and skills (Perry et al., 1999). Dubberke et al. (2008) found that teachers with a strongly transmissive view on teaching and learning create a less cognitively activating learning environment, which has a negative effect on student achievement.

It should be noted that teachers may have mixed as well as contradictory attitudes depending on the context in which these attitudes are activated (Snider and Roehl, 2007; Fives and Buehl, 2012). More specifically, research suggests that constructivist and transmissive attitudes are not aligned on a unidimensional scale with two opposite views (e.g., Hermans et al., 2008; Voss et al., 2013). Instead, teachers can exhibit highly constructivist and transmissive attitudes (e.g., Voss et al., 2013) at the same time.

Teacher attitudes are relevant for a teacher's well-being. When a teacher's attitudes about teaching and learning are congruent with their actions, they report a higher level of satisfaction (Buehl and Beck, 2015). It is however, especially preservice teachers who seem to encounter dissonant attitudes and practices during their first in-service experiences in schools, because they have often learned constructivist views on teaching in university, which may contradict with views encountered in real-world teaching situations (Rimm-Kaufmann et al., 2006; Zaruba et al., 2019). This may increase teachers' risk of experiencing a reality shock 
(Dicke et al., 2016; see also Kim and Cho, 2014), which is associated with a decrease in constructivist attitudes (Voss and Kunter, 2020).

\section{The Development of Preservice Teachers' Attitudes}

One argument for addressing preservice teachers' transmissive and constructivist attitudes is to find out how and why teacher attitudes develop over the course of teacher training programs. From a theoretical perspective, it has been argued that preservice teachers' attitudes are based on personal experiences from when they were students themselves and are shaped during teacher training (Fives et al., 2015; Gregoire Gill and Hardin, 2015). The available research however, draws no clear picture of the development of preservice teachers' attitudes and the factors involved. Although preservice teachers' attitudes are considered to be very stable (Pajares, 1992; Nettle, 1998; Skott, 2015), there is enough evidence to suggest that preservice teachers' attitudes develop to some extent during teacher training (see Richardson, 1996; Fives et al., 2015 for reviews).

Experiences in the field in the form of student teaching seem to be a factor in developing attitudes (Fives et al., 2015). A study by Zaruba et al. (2018) showed that self-reported constructivist and transmissive attitudes remained stable after a semester of student teaching in most preservice teachers. However, a sub-sample of students developed more constructivist attitudes, while another sub-sample of students adopted less constructivist attitudes (Zaruba et al., 2018). A recent study by Voss and Kunter (2020), which explored experiences of a "reality shock" in new teachers, identified a significant decrease in constructivist beliefs in new teachers. Decker et al. (2015) found in turn, that guided reflection in seminars may help trainee teachers develop constructivist attitudes during their induction phase.

To our knowledge, there is no study yet that in addition to assessing explicit attitudes has dealt with the development of implicit constructivist and transmissive attitudes. Explicit measures of attitudes should thus be complemented by implicit measures in order to assess preservice teachers' attitudes more comprehensively.

\section{Implicit and Explicit Attitude Assessment The Associative-Propositional Model}

One theoretical model that elaborates on and explains the relationship between implicit and explicit attitudes is the associative-propositional evaluation model (APE) by Gawronski and Bodenhausen (2006). According to the APE model, explicit and implicit attitudes are considered to be a result of two different but interrelated ways of information processing. Gawronski and Bodenhausen (2006) describe implicit attitudes as "automatic affective reactions resulting from the particular associations that are activated automatically when one encounters a relevant stimulus" (p. 693). Any given input stimulus can therefore lead to an automatic affective reaction. Those automatic affective reactions require little cognitive capacity and are often described as fast and spontaneous "gut feelings" (Strack and Deutsch, 2004). For instance, the stimulus "learning facts by heart" can activate a preservice teacher's personal associations (e.g., memories of personal learning success/failure in school when working with this technique) and may result in pleasant or unpleasant feelings.

Explicit attitudes, on the other hand, can be derived from answers to questions such as "Do you like learning facts by heart as a method in the classroom?" The APE model assumes that finding an answer to that question requires a different way of processing information (Gawronski and Bodenhausen, 2006). The authors suggest that through propositional reasoning, an individual may establish an explicit attitude (see also Strack and Deutsch, 2004). This process requires the person to examine their beliefs and values and validate the automatic implicit association to the given stimulus. The implicit association here is set as a default mode, which needs thoughtful deliberation to be expressed as an explicit attitude - deliberation that requires more cognitive capacity (Gawronski and Bodenhausen, 2006).

It is important to note that an explicit attitude can, depending on the result of the validation, contradict the implicit attitude (Gawronski and Bodenhausen, 2006). This may result in socially desirable response behavior towards oneself or others and respondents may also be unaware of their implicit attitude (Wittenbrink and Schwarz, 2007).

\section{The Challenge of Assessing Teacher Attitudes}

A challenge of attitude research is the difficulty of operationalizing and assessing attitudes. While standardized tests can establish a teacher's knowledge (e.g., the content knowledge test for science assessment, Mikeska et al., 2018), it is much more difficult to measure attitudes (Schraw and Olafson, 2015). Clearly defined attitude constructs (e.g., inclusion) are usually assessed with self-report measures (e.g., Seifried and Heyl, 2016).

A common limitation of self-report measures is socially desirable response behavior (Krosnick et al., 2005). Attitudes about sensitive or value-laden topics, such as inclusion or giftedness, are especially vulnerable to social desirability bias (Preckel et al., 2015; Lüke and Grosche, 2017). Attitudes towards teaching and learning, which are the focus of the present study, can also be subject to social desirability bias, with a constructivist view of teaching often being seen as more desirable than a transmissive view on teaching (Terhart, 2003; Juvova et al., 2015). This suggests that there could be a risk of bias (De Houwer, 2006) when explicitly measuring teacher attitudes on constructivism and transmission.

Indirect measures aim to overcome strategic responses. These methods infer the attitude "by comparing behavioral responses across two or more conditions" (Bar-Anan and Nosek, 2014, p. 668). One of those methods, the Implicit Association Test (IAT; Greenwald et al., 1998), has been tested extensively and shows strong psychometric qualities (e.g., Greenwald et al., 2009) but requires two dichotomous attitude objects (e.g., two political parties) for assessment (Bar-Anan and Nosek, 2014). The Single-Target Implicit Association Test (ST-IAT; Karpinski and Steinman, 2006) on the other hand, is sensitive to singlecategory attitude objects (Karpinski and Steinman, 2006) and can thus be used in the context of general preservice teachers' 


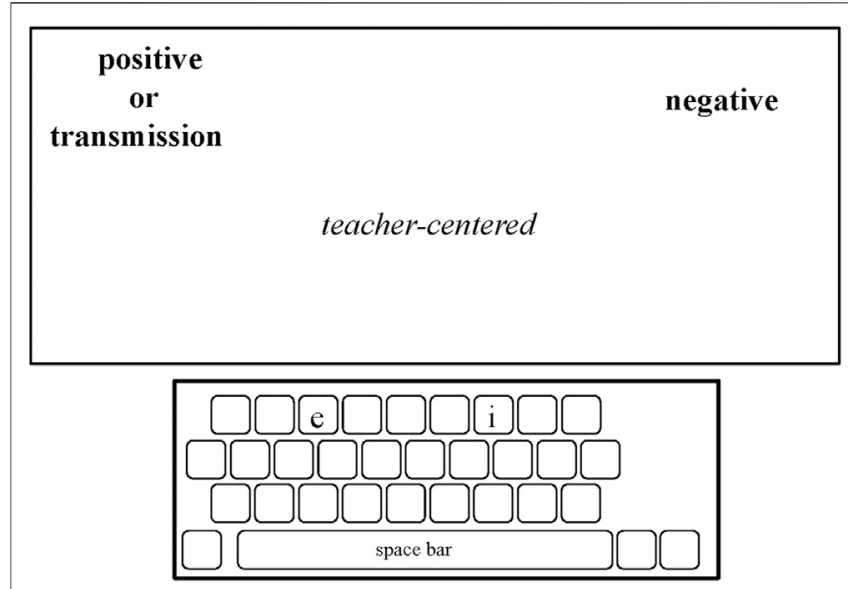

Correct answer: Keyboard press - e

Incorrect answer: Keyboard press - $\mathrm{i}$

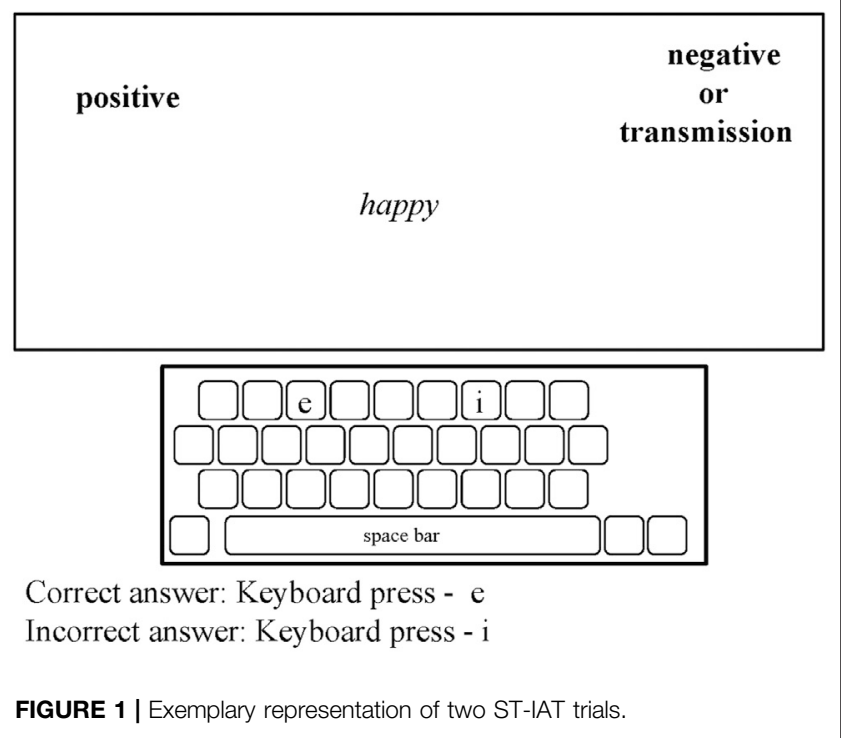

attitudes, where it is possible for positive attitudes towards constructivism and transmission to be held simultaneously (Snider and Roehl, 2007; Fives and Buehl, 2012).

In ST-IATs, participants are asked to quickly categorize stimulus words from a target category (e.g., constructivism), as well as a positive and a negative category in a computerized test. The ST-IAT consists of different blocks of categorization trials. The computer screen displays the target category and one evaluative category on one side (e.g., constructivism + positive), and the other evaluative category on the opposite side (e.g., negative) (see Figure 1). Stimuli appear in the center of the screen and have to be assigned to the correct category as quickly and correctly as possible. The target category changes position for another block of trials. Faster classifications of stimuli to, for example, a combined block of constructivism and positive than a combined block of constructivism and negative indicate more positive implicit associations towards the concept of constructivism. The implicit association (ST-
IAT effect) is expressed as a $D$-score (Greenwald et al., 2003) that is not to be confused with Cohen's $d$.

\section{Preservice Teachers' Implicit Attitudes}

While implicit measures are well-established in social psychology (Fazio and Olson, 2003), "the consideration of teachers' implicit attitudes is still in its infancy" (Pit-Ten Cate and Glock, 2019, p. 2). Although researchers claim that implicit attitudes play a decisive role in a teacher's professional development (e.g., Wilcox-Herzog et al., 2015), research on implicit teacher attitudes remains scant, with assessment methods almost entirely focusing on explicit measures (Schraw and Olafson, 2015). However, some recent studies on preservice teachers' attitudes towards value-laden pedagogical issues, such as inclusion or giftedness, use implicit measures to deal with social desirability (Lüke and Grosche, 2017). Preckel et al. (2015) tested preservice teachers' attitudes towards giftedness with a ST-IAT and affective priming tasks. They found that preservice teachers associated high intelligence with gifted students but also tended to ascribe adjustment problems to male gifted students. Affective priming with stimuli associated with adjustment problems activated negative attitudes towards male gifted students. Lautenbach and Antoniewicz (2018) analyzed explicit and implicit attitudes of preservice teachers towards inclusion. They found slightly positive implicit attitudes towards inclusion $(D$-Score $=0.13)$, while explicit attitudes towards inclusions were positive (Lautenbach and Antoniewicz, 2018). Lüke and Grosche (2018) also tested preservice teachers' implicit attitudes towards inclusion with a ST-IAT, which turned out to be neutral $(D$-Score $=0.03)$. The preservice teachers' explicit attitudes towards inclusion, on the other hand, were positive.

Experience-based formats in teacher preparation, such as student teaching, represent a crucial element in teacher attitude development (Fives et al., 2015), and may affect implicit attitudes towards teaching and learning. If a preservice teacher has positive experiences when teaching by rote, positive associations towards this method may become manifest and thus implicit attitudes may change in favor of a positive "gut feeling" towards this teaching method. Explicit attitudes towards teaching and learning may remain stable because the preservice teacher may not have processed the relevant experience through propositional reasoning or may be subject to social desirability bias.

\section{THE PRESENT STUDY}

Research on teachers' attitudes towards teaching and learning is usually assessed using self-report measures (Schraw and Olafson, 2015). Although this research is informative, it is limited by the fact that teachers' explicit attitudes may differ from their implicit attitudes (Lautenbach and Antoniewicz, 2018), possibly due to a social desirability bias (Nosek, 2007; Lüke and Grosche, 2017).

In the present study, we will expand the scope of teachers' attitude research by examining preservice teachers' explicit and implicit constructivist and transmissive attitudes. We will 
therefore describe a ST-IAT developed to assess the multidimensional constructs of constructivist and transmissive attitudes. In addition, we will aim to shed light on preservice teachers' implicit and explicit constructivist and transmissive attitudes near the end of their studies and on attitude development during student teaching as compared to a regular semester attending university lectures.

The following questions guided our study:

1. How do preservice teachers evaluate constructivist and transmissive views of teaching at the end of their master's studies?

2. To what extent do ST-IATs reliably measure preservice teachers' constructivist and transmissive views on teaching?

3. To what extent do explicit and implicit measures differentially assess preservice teachers' constructivist and transmissive views on teaching?

4. Do explicit and implicit measures of preservice teachers' constructivist and transmissive views on teaching develop during student teaching?

\section{MATERIALS AND METHODS}

\section{Sample}

The study was conducted in Potsdam (Germany). In Germany, teacher education consists of two successive phases. The first phase comprises a 4- to 5-year-long academic program at university level, after which candidates obtain a master's degree upon successful completion. This is followed by the second phase of 12-24 months of in-service practical training. The degree to which pedagogical work placements are part of the first phase of teacher education differs among universities.

Our sample consisted of $N=100$ preservice teachers enrolled in a teacher training program (master's studies at university level) at the University of Potsdam, Germany. Half of our sample the internship group ( $n=50$ preservice teachers) completed a semester of student teaching. The other half of our sample the lecture group ( $n=50$ preservice teachers) continued their master's studies taking regular lectures and classes.

All preservice teachers were tested twice, once at the beginning of the semester in September or October $2017\left(\mathrm{~T}_{1}\right)$ and a second time at the end of the semester in February 2018 $\left(\mathrm{T}_{2}\right)$. At $\mathrm{T}_{1}$, the preservice teachers' age in the internship group was $M=26.78(S D=3.60)$. On average, they were in their third master's semester $(M=3.44, S D=0.97)$. Preservice teachers in the lecture group were $M=25.04(S D=2.66)$ years old and were in their second semester $M=1.76(S D=0.95)$. The difference in age between both groups was statistically significant, $t(98)=$ 2.72, $p=0.008, d=0.55$. Of $N=100$ participants, $73 \%$ were female. The gender ratio is comparable to the gender ratio of inservice teachers in schools providing general education in the federal state of Brandenburg, in which the study took place (78\% women) (Amt für Statistik Berlin-Brandenburg, 2017). The two groups did not differ significantly in gender ratio, $\chi^{2}(1)=0.45$, $p=0.499$.
The internship group completed a semester of student teaching, which lasted 16 weeks (14 weeks at a school, plus two weeks of preparation and follow-up seminars at university) and is a mandatory part of the master's program of teacher training at the University of Potsdam, Germany. The student teaching semester includes additional university seminars, sitting in on classes, and assisting teachers (66 lessons) as well as the students planning and teaching fifty lessons on their own. While in school, individual teachers from the school in question mentor each preservice teacher.

\section{Instruments}

\section{Explicit Attitude Measures}

We used the scales transmission and construction from the Questionnaire for four teachers' beliefs (Q4TB) developed by Schlichter (2012). As opposed to other questionnaires, which are able to measure transmissive and constructivist teachers' attitudes in German (Staub and Stern, 2002; Seidel and Meyer, 2003; Baumert et al., 2009), Schlichter's (2012) scales do not have a mathematics or science focus and could thus be used for our sample, which integrates preservice teachers of different subjects. The scale measuring explicit constructivist attitudes (example: To me, teaching means creating a learning environment in which students can follow their individual learning paths.) and explicit transmissive attitudes (example: To me, teaching means presenting lesson content in a way that students can comprehend well.) each comprises nine items. Participants used a Likert scale ranging from one (strongly disagree) to five (strongly agree). Reliabilities were acceptable to very good (Table 1).

\section{Implicit Attitude Measures}

To measure implicit attitudes, we used two Single-Target Implicit Association Tests (ST-IAT; Bluemke and Friese, 2008), one for the target category constructivism and one for the target category transmission. The ST-IAT is a computer test measuring the strength of associations between one target concept (i.e., transmission or constructivism) and two attribute categories (positive and negative). The underlying assumption with implicit measures is that the stronger the association between the target concept and one evaluative concept is, the faster and more accurate the reaction will be.

The participants were seated in front of a computer running OpenSR software (Svegliato, 2017), which we adapted for the purpose of the ST-IAT. Before each test, participants were shown the input stimuli and the categories they belonged to. They were instructed to respond as quickly and correctly as possible. Each test was divided into four parts. The first part was a practice block containing 25 trials. The stimulus word was displayed in the screen's center and had to be assigned to the correct side (e.g., transmissive + positive vs. negative) (see Figure 1). The stimuli appeared in a random order. Stimulus words were presented in a 7:5:5 ratio displaying more target concept words than attitude stimuli to balance both left- and right-handed responses. Attributing the stimulus to the left or right side of the screen was realized by pressing the " $\mathrm{e}$ " or " $\mathrm{i}$ " keys. A red cross indicated a mistake until the word had been assigned correctly. The practice 
TABLE 1 | Reliability of implicit and explicit measures at $T_{1}$ (beginning of semester) and $T_{2}$ (end of semester)

\begin{tabular}{|c|c|c|c|c|c|c|}
\hline & \multicolumn{3}{|c|}{ Lecture group (regular master's courses) } & \multicolumn{3}{|c|}{ Internship group (student teaching) } \\
\hline & \multicolumn{3}{|c|}{ Cronbach's $\alpha$} & \multicolumn{3}{|c|}{ Cronbach's $\alpha$} \\
\hline & $T_{1}$ & $\mathbf{T}_{2}$ & Rank stability (Spearman $r$ ) & $\mathbf{T}_{1}$ & $\mathbf{T}_{2}$ & Rank stability (Spearman $r$ ) \\
\hline \multicolumn{7}{|l|}{ Explicit measures } \\
\hline Transmissive & 0.85 & 0.90 & $0.59^{\star}$ & 0.88 & 0.83 & $0.52^{\star}$ \\
\hline Constructivist & 0.63 & 0.84 & $0.33^{\star \star \star}$ & 0.71 & 0.87 & $0.41^{*}$ \\
\hline \multicolumn{7}{|l|}{ Implicit measures } \\
\hline Transmissive & 0.72 & 0.58 & $0.50^{\star}$ & 0.72 & 0.79 & 0.21 \\
\hline Constructivist & 0.68 & 0.57 & $0.52^{*}$ & 0.72 & 0.72 & 0.19 \\
\hline
\end{tabular}

block was followed by a test block with the same attribution of categories on screen. This block contained 74 trials. After that, the target category (transmissive in our example) changed position (negative vs. transmissive + positive). Participants practiced the classification of stimuli to the changed category positions in 25 trials and were subsequently tested in 74 further trials.

Reliabilities for both tests were calculated following Karpinski and Steinman (2006). Reliabilities were satisfactory for all tests (see Table 1), taking into consideration the fact that ST-IAT reliabilities are generally lower than those of regular IATs ( $\alpha=0.70$ or lower) (Karpinski and Steinman, 2006; Bluemke and Friese, 2008).

IAT results are commonly expressed as $D$-scores (Greenwald et al., 2003). The $D$-score can obtain values between -2 and +2 , usually ranging between -1 and +1 . The higher the $D$-score, the more positive the association towards the target concept. We calculated a $D$-score based on Bluemke and Friese (2008) as an indicator of the implicit association of an individual with the target concept. This included deleting all training and error trials. All extreme latencies below $300 \mathrm{~ms}$ and above $3,000 \mathrm{~ms}$ were removed as errors. The first trial of each block was considered a trial run and thus deleted. Participants were only included when a minimum of $80 \%$ of the data was error-free.

All participants reached the inclusion criteria and could thus be included in the sample. We subtracted a participants' mean response latency of the second combined block (i.e., transmission + negative) from the first combined block (i.e., transmission + positive). The difference was then divided by the standard deviation of all latencies of correct responses in both blocks.

We carried out a pilot study to select the stimuli. Following a brainstorming session, the research team compiled a list of words that they associated with one of the target concepts of constructivist or transmissive teaching. The outcome of $N=$ 17 words for transmission and $N=15$ words for constructivism were then randomized and listed up in a questionnaire. This questionnaire was then given to $N=19$ expert researchers in the field of educational sciences. After having read a definition of the concepts in question, the experts were asked to rate all words on a Likert-scale ranging from $1=$ transmissive to $7=$ constructivist. Five words representing constructivism and five words representing transmission (Table 2) were chosen after setting a cut-off
TABLE 2 | Stimuli used in ST-IAT transmission and ST-IAT constructivism.

\begin{tabular}{llll}
\multicolumn{4}{c}{ Target concept } \\
\hline Transmission & Constructivism & $\begin{array}{l}\text { Positive } \\
\text { Adjectives }\end{array}$ & $\begin{array}{l}\text { Negative } \\
\text { Adjectives }\end{array}$ \\
\hline Teacher-centered & $\begin{array}{l}\text { Problem- } \\
\text { oriented } \\
\text { Autonomous }\end{array}$ & Happy & Ruthless \\
$\begin{array}{l}\text { Prescribe } \\
\text { Learn by rote }\end{array}$ & $\begin{array}{l}\text { Hellenge } \\
\text { Reflect }\end{array}$ & $\begin{array}{l}\text { Congenial } \\
\text { Pleased }\end{array}$ & Pitiless \\
$\begin{array}{l}\text { Definitions } \\
\text { To quiz students }\end{array}$ & Self-regulated & Fair & Malicious \\
& & Warm hearted & Evil \\
& & Honest & Abusive
\end{tabular}

Note. Positive and negative adjectives were successfully used in a ST-IAT study by Preckel et al. (2015). German original stimuli for transmission: lehrergesteuert, vorgeben, auswendig lernen, Definitionen lernen, abfragen. German original stimuli for constructivism: problemorientiert, eigenverantwortlich, hinterfragen, reflektieren, selbstgesteuert.

value indicating the words that were strongly associated with the concept of transmission and those that were strongly associated with the concept of constructivism. The evaluative categories (positive and negative) were each represented by seven adjectives (Table 2) that had been successfully used in a ST-IAT study by Preckel et al. (2015).

\section{Demographics}

In a demographics section of the questionnaire, we asked participants about their age, gender and the number of master's semesters they had already completed.

\section{Procedure}

We used email to contact all preservice teachers who were enrolled in the master's program and were about to start a semester of student teaching, asking them to participate in a study on teacher's attitudes towards teaching and learning. They were told that the study would comprise filling out a questionnaire and taking two ST-IATs before and after their semester of student teaching. Additionally, we disseminated this information by visiting master's students in lectures and seminars 
TABLE 3 | Descriptive statistics of implicit and explicit measures at $T_{1}$ (beginning of semester) and $T_{2}$ (end of semester).

\begin{tabular}{|c|c|c|c|c|c|c|c|c|}
\hline & \multicolumn{4}{|c|}{ Lecture group (regular master's courses) } & \multicolumn{4}{|c|}{ Internship group (student teaching) } \\
\hline & \multicolumn{2}{|c|}{$\mathbf{T}_{\mathbf{1}}$} & \multicolumn{2}{|c|}{$\mathbf{T}_{\mathbf{2}}$} & \multicolumn{2}{|c|}{$\mathbf{T}_{\mathbf{1}}$} & \multicolumn{2}{|c|}{$\mathbf{T}_{2}$} \\
\hline & $M$ & $S D$ & $M$ & $S D$ & $M$ & $S D$ & $M$ & $S D$ \\
\hline \multicolumn{9}{|l|}{ Explicit measures } \\
\hline Transmissive & 4.08 & 0.62 & 4.00 & 0.60 & 4.30 & 0.50 & 4.14 & 0.71 \\
\hline Constructivist & 4.22 & 0.36 & 4.04 & 0.60 & 4.11 & 0.37 & 4.08 & 0.50 \\
\hline \multicolumn{9}{|l|}{ Implicit measures } \\
\hline Transmissive & 0.28 & 0.30 & 0.29 & 0.32 & 0.26 & 0.30 & 0.33 & 0.30 \\
\hline Constructivist & 0.39 & 0.29 & 0.40 & 0.26 & 0.40 & 0.27 & 0.36 & 0.27 \\
\hline
\end{tabular}

and asking individual lecturers to forward an email about the study to enrolled students.

All participants $(N=100)$ attended test sessions at the beginning of the semester $\left(T_{1}\right)$ (September/October 2017) to assess how these preservice teachers evaluated constructivist and transmissive views of teaching near the end of their teacher training and to examine to what extent explicit and implicit measures are able to assess preservice teachers' transmissive and constructivist views on teaching in a differentiated way.

We tested both groups separately at $T_{1}$ and the end of the semester in February $2018\left(\mathrm{~T}_{2}\right)$ to investigate whether or not preservice teachers' attitudes develop after student teaching (internship group, $n=50$ and lecture group, $n=50$ ) and to what extent implicit and explicit measures reliably assess preservice teachers' constructivist and transmissive views on teaching (internship group, $n=50$ and lecture group, $n=50$ ).

Before starting the test, participants were informed about the study procedures and asked to fill out an informed consent form. Participants first took the two ST-IATs (transmission and constructivism) before filling out the questionnaire. They were tested in small groups or alone to minimize distraction. The STIATs were balanced to avoid position effects.

Of the 127 participants that came to the first testing session, 118 also came to the second session (93\%). Final analyses were based on the data of 100 participants (50 each in the test and lecture group), who filled out all questions in the questionnaire and fulfilled all ST-IAT tasks correctly (79\%).

\section{Statistical Analyses and Data Processing}

In order to evaluate implicit attitudes towards transmission and constructivism, we calculated the ST-IAT's D-scores. We then calculated the internal consistencies of the ST-IATs (see implicit attitude measures) to examine whether or not the STIATs can reliably measure implicit attitudes. In order to test our research questions, we ran two sets of multivariate analysis of variance (MANOVA) on the implicit and on the explicit measures with group of participants (lecture group and internship group) as between-person factors, and time ( $\mathrm{T}_{1}$ and $\mathrm{T}_{2}$ ) and dimension (transmission and constructivism) as within-person factors. Implicit and explicit measures were modeled in two separate MANOVAs because they were measured on different scales. We also ran two-tailed Spearman correlations to examine rank stability (test-retest

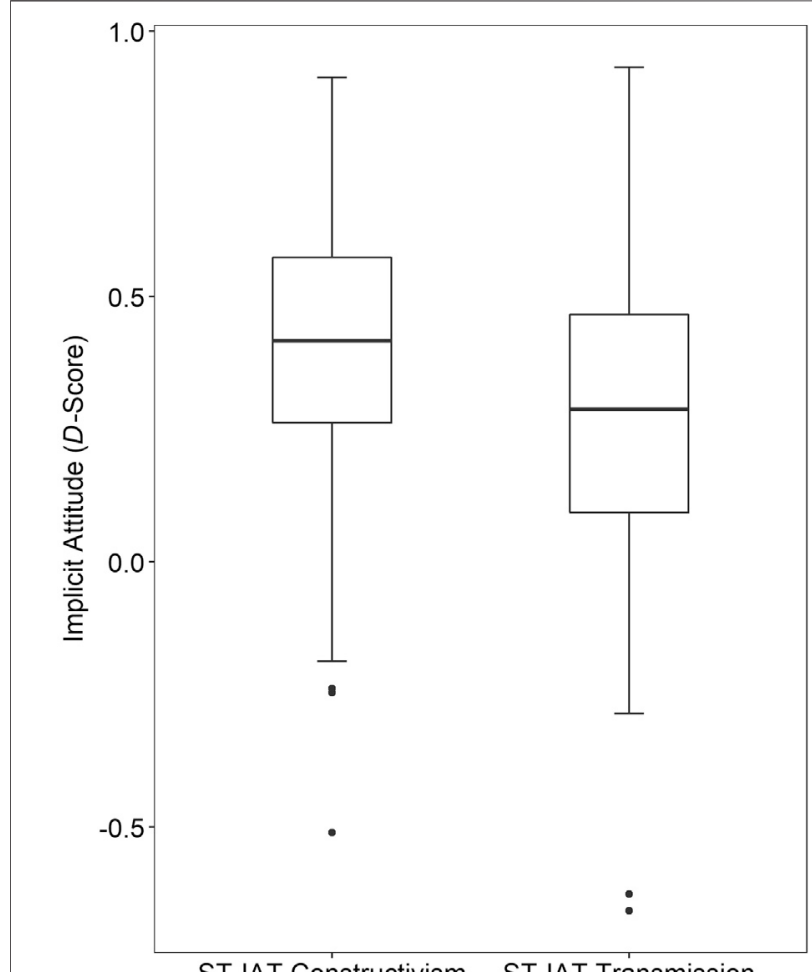

ST-IAT Constructivism ST-IAT Transmission

FIGURE 2 | Implicit constructivist and transmissive attitudes of all participants at $T_{1}(N=100)$.

correlation) to check for possible inter-individual differences in the development of attitudes, which would not be detected by comparing mean differences.

\section{RESULTS}

\section{How Do Preservice Teachers Evaluate Constructivist and Transmissive Views of Teaching at the End of Their Master's Studies?}

Full descriptive data are given in Table 3 and illustrated in Figures 2, 3. With respect to the explicit measures, 


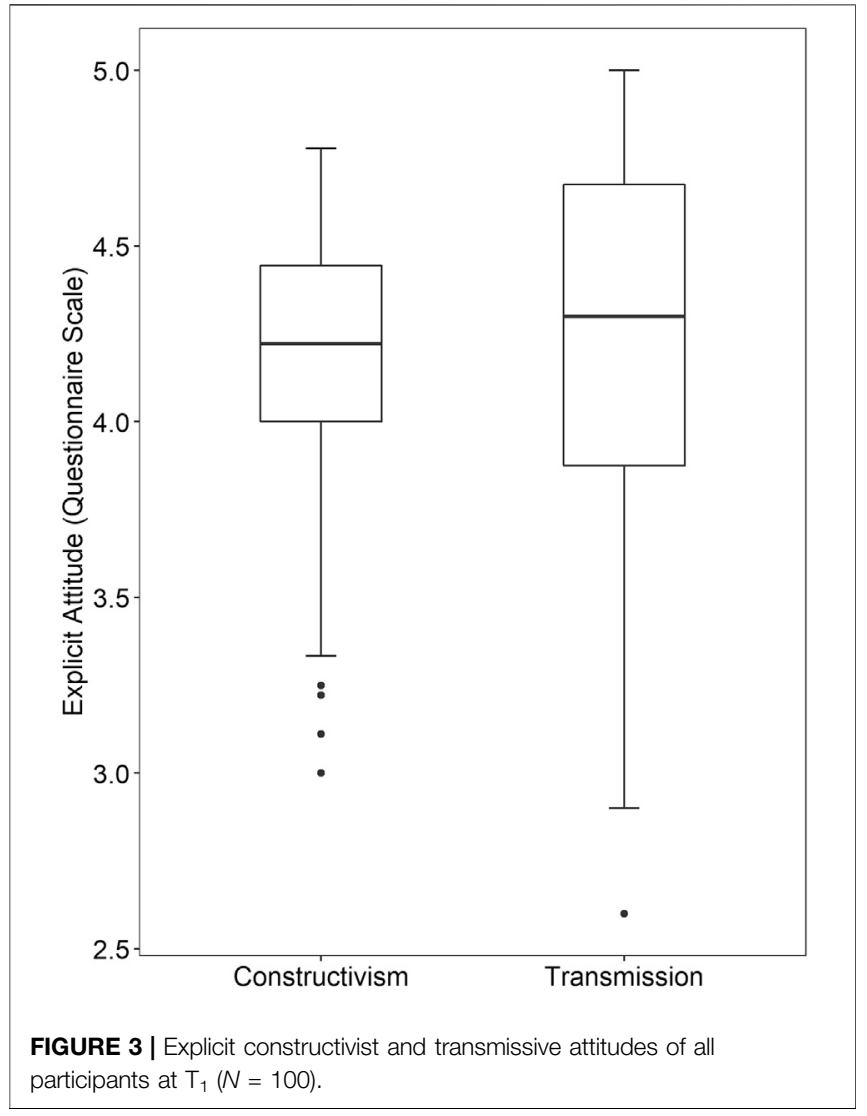

TABLE 4 | Predicting implicit measures.

\begin{tabular}{lcccc}
\hline Effect & $\boldsymbol{F}$ & df & $\boldsymbol{p}$ & Partial eta squared \\
\hline Time $\left(\mathrm{T}_{1}\right.$ vs. $\left.\mathrm{T}_{2}\right)$ & 0.219 & 1,98 & 0.641 & 0.002 \\
Dimension $(\mathrm{T}$ vs. $\mathrm{C})$ & 13.275 & 1,98 & 0.000 & 0.119 \\
Group & 0.002 & 1 & 0.967 & 0.000 \\
Time $\times$ Group & 0.147 & 1,98 & 0.702 & 0.002 \\
Dimension $\times$ Group & 0.000 & 1,98 & 0.985 & 0.000 \\
Time $\times$ Dimension & 1.597 & 1,98 & 0.209 & 0.016 \\
Time $\times$ Dimension $\times$ Group & 1.472 & 1,98 & 0.228 & 0.015
\end{tabular}

Note. Dimension ( $T$ = Transmission, $C=$ Constructivism), Group (Lecture group vs. Internship group).

participants $(N=100)$ strongly agreed with both the concept of constructivism and transmission (explicit measures: $M_{T 1}$ Transmission $=4.19, S D=0.57 ; M_{T 1 \text { Constructivism }}=4.17, S D=$ 0.36). On the implicit level, participants held reasonably positive attitudes towards both the concept of constructivism and transmission (implicit measures: $M_{T 1}$ Transmission $=0.27, S D=0.30 ; M_{T 1}$ Constructivism $=0.40$, $S D=0.28)$.
TABLE 5 | Predicting explicit measures.

\begin{tabular}{lcccc}
\hline Effect & $\boldsymbol{F}$ & $\mathbf{d f}$ & $\boldsymbol{p}$ & Partial eta squared \\
\hline Time $\left(\mathrm{T}_{1}\right.$ vs. $\left.\mathrm{T}_{2}\right)$ & 5.070 & 1,98 & 0.027 & 0.049 \\
Dimension $(\mathrm{T}$ vs. C) & 0.076 & 1,98 & 0.784 & 0.001 \\
Group & 1.118 & 1 & 0.293 & 0.011 \\
Time $\times$ Group & 0.105 & 1,98 & 0.747 & 0.001 \\
Dimension $\times$ Group & 3.154 & 1,98 & 0.079 & 0.031 \\
Time $\times$ Dimension & 0.045 & 1,98 & 0.833 & 0.000 \\
Time $\times$ Dimension $\times$ Group & 3.509 & 1,98 & 0.064 & 0.035
\end{tabular}

Note. Dimension ( $T$ = Transmission, $C=$ Constructivism), Group (Lecture group vs. Internship group).

\section{To What Extent Do ST-IATs Reliably Measure Preservice Teachers' Transmissive and Constructivist Views on Teaching?}

Both implicit measures showed acceptable reliabilities ranging from $\alpha=0.58$ to $\alpha=0.79$ for the ST-IAT measuring transmissive attitudes and from $\alpha=0.57$ to $\alpha=0.72$ for the ST-IAT measuring constructivist attitudes (see Table 1). In Table 4, results of a MANOVA on the implicit measures are depicted with group of participants (lecture group and internship group) as between-person factor, and time $\left(\mathrm{T}_{1}\right.$ and $\mathrm{T}_{2}$ ) and dimension (transmission and constructivism) as within-person factors. Particularly relevant for our research question is the non-significant main effect of time, $F(1,98)=0.219, p=0.641, \eta 2=0.002$. Thus, there were no significant changes in the mean values of implicit transmissive attitudes and implicit constructivist attitudes.

For the evaluation of rank stabilities of our implicit measures, we focused on the lecture group, which in contrast to the internship group had not yet participated in the in-school training believed to alter students' implicit attitudes. We found that preservice teachers' implicit constructivist attitudes remained largely stable across time with temporal stabilities ranging from $r_{t t}=0.50$ for transmissive attitudes to $r_{t t}=0.52$ for constructivist attitudes over a period of four months.

\section{To What Extent Do Explicit and Implicit Measures Differentially Assess Preservice Teachers' Constructivist and Transmissive Views on Teaching?}

The MANOVA on the implicit measures (Table 4) showed a significant main effect of dimension (transmission and constructivism), $F(1,98)=13.275, p=0.000, \eta 2=0.119$. Table 5 summarizes the findings of a MANOVA on the explicit measures with group of participants (lecture group and internship group) as between-person factor, and time ( $\mathrm{T}_{1}$ and $\mathrm{T}_{2}$ ) and dimension (transmission and constructivism) as within-person factors. We found no significant effect of dimension, $F(1,98)=0.076, p=0.784, \eta 2=0.001$. 


\section{Do Explicit and Implicit Measures of Preservice Teachers' Constructivist and Transmissive Views on Teaching Develop During a Semester of Student Teaching?}

The MANOVA on the implicit measures (Table 4) yielded no significant main effect of time, $F(1,98)=0.219, p=0.641, \eta 2=$ 0.002 , and non-significant interactions of Time $\mathrm{x}$ Group, $F(1,98)$ $=0.147, p=0.702, \eta 2=0.002$, and Time $\mathrm{x}$ Dimension $\mathrm{x}$ Group, $F(1,98)=1.472, p=0.228, \eta 2=0.015$. However, the MANOVA on the explicit measures (Table 5) showed a significant main effect of time, $F(1,98)=5.070, p=0.027, \eta 2=0.049$. The interaction effects of Time $\mathrm{x}$ Group, $F(1,98)=0.105, p=0.747, \eta 2$ $=0.001$, and Time $\mathrm{x}$ Dimension $\mathrm{x}$ Group, $F(1,98)=3.509, p=$ $0.064, \eta 2=0.035$, were not significant. Thus, preservice teachers in both groups reported higher explicit attitudes at $\mathrm{T}_{2}$ than at $\mathrm{T}_{1}$ (Table 3).

Concerning the rank stabilities, we found significant test-retest correlations of the explicit measures of constructivism and transmission in both groups $(0.33 \leq|r| \leq 0.59$; Table 1). Testretest correlations of the lecture group's implicit attitudes were also significant $(0.50 \leq|r| \leq 0.52$; Table 1). However, test-retest correlations of the internship group's implicit measures were not significantly correlated $(0.19 \leq|r| \leq 0.21$; Table 1$)$.

\section{DISCUSSION}

The aim of this study was to examine preservice teachers' implicit and explicit constructivist and transmissive attitudes towards teaching, while attempting to overcome common limitations in attitude research, such as strategic responding (Nosek, 2007; Lüke and Grosche, 2017), as well as to assess preservice teachers attitudes more comprehensively (e.g., Wilcox-Herzog et al., 2015).

\section{Preservice Teachers Are in Favor of Both Constructivism and Transmission}

Preservice teachers strongly agreed with the concept of transmission and constructivism on the explicit level (see Figure 3). We were also able to identify positive implicit attitudes towards transmission and constructivism (see Figure 2). Our findings support the theory of a twodimensional attitude structure. While authors often argue that teachers have either transmissive or constructivist attitudes towards teaching and learning (see e.g., Fives et al., 2015), studies have found that preservice teachers can have both a constructivist and a transmissive view on teaching and learning at the same time (e.g., Voss et al., 2013; Skott, 2015; Zaruba et al., 2018). This can be explained by the fact that attitudes "differ across contexts" (Skott, 2015, p. 23), meaning that they are activated depending on the situation the teacher in question encounters (Gawronski and Bodenhausen, 2006; Fives et al., 2015; Skott, 2015) and could indicate an intention to adaptive teaching.
In a survey of K-12 teachers, Snider and Roehl (2007), (p. 883) found that teachers' attitudes did not "adhere to a single pedagogical philosophy" but were "highly contextual and idiosyncratic." The authors suggest that teachers base decisions for teaching on contextual factors, intuition and practical knowledge (Lortie, 1975) instead of a specific theoretical basis (like constructivism). In an abstract test situation, they may therefore express a favorable position towards both the concept of constructivism and transmission, as they may find items of both scales that remind them of teaching situations they considered successful. For instance, the item of the transmission scale "To me, teaching means presenting lesson content in a way that students can comprehend well" could be understood as referring to practical characteristics of effective teaching such as lesson presentation skills (e.g., clarity of explanation) (Perrot, 1982). And the item "To me, teaching means creating a learning environment in which students can follow their individual learning paths" from the constructivism scale could be understood as reflecting a constructivist attitude acquired in the university context.

\section{The Reliability of the ST-IATs}

Implicit attitude measures remained stable over time $(F(1,98)$ $=0.219, p=0.641, \eta 2=0.002)$. Also, the reliabilities of the implicit test measures proved to be acceptable on average throughout all tests in both groups (Table 1). For an STIAT, this can be considered to be a positive result. Usually, reliabilities of ST-IATs are lower than that expected of traditional IATs (Bluemke and Friese, 2008). Compared to other implicit measures, the internal consistencies of the STIAT for transmission and constructivism can be considered comparatively strong. Bar-Anan and Nosek (2014) tested the psychometric qualities of seven indirect attitude measures. Indirect measures like the Evaluative Priming Task (Fazio et al., 1995) and the Sorting Paired Features Task (BarAnan and Nosek, 2014) exhibited internal consistencies between $\alpha=0.53$ and $\alpha=0.57$.

Temporal stabilities of the implicit measures for the lecture group (Table 1) over a period of four months showed significant values in the range of $r_{t t}=0.50$ to $r_{t t}=0.52$, which are typical for IAT measures (Egloff et al., 2005). Egloff et al. (2005), among others, tested the temporal stability of an anxiety-IAT, which yielded results in the range of $r_{t t}=0.47$ to $r_{t t}=0.62$, regardless of the time interval between measurements (one week to one year). Bar-Anan and Nosek (2014) found a test-retest correlation of $r_{t t}=0.48$, most retests having been taken within $24 \mathrm{~h}$ after the first time the measurement was taken. On the basis of these results, we can reason that we were able to construct a test with which we can reliably measure student teachers' implicit attitudes towards constructivism and transmission. In the internship group, we found no significant test-retest correlations in both the implicit measure of constructivism and the implicit measure of transmission, which indicates variance in the automatic evaluation of both concepts after a semester of student teaching. 


\section{The Differential Capabilities of Implicit and Explicit Measures}

Concerning the question of whether implicit and explicit attitudes towards constructivist and transmissive views on teaching differ, we found discrepancies between them when assessed using implicit measures. As explicit measures yielded high approval rates of both the concept of transmission and of constructivism, the discrepancy identified in implicit attitudes is particularly interesting. One could assume that the explicit instrument (Schlichter, 2012) in our sample was unable to clearly differentiate in the upper range (ceiling effect) with respect to mean values. Another reason for this pattern of results could be a socially desirable response to the explicit attitudes being asked about, since items of both the transmission and constructivism scale could evoke characteristics of successful teaching practice (Perrot, 1982).

In IATs, however, responding in a socially desirable way is more difficult. Even though participants can theoretically manipulate IATs in order to present themselves in a positive light (Fiedler and Bluemke, 2005), the complexity of the task and the lack of understanding of the underlying assumptions complicate such attempts at deception. To add to this, the default interventionist logic of the APE model emphasizes the idea that implicit attitudes are not validated by information. They resemble affective "gut reactions," which can be, but are not necessarily, altered through explicit deliberation. Future studies could aim to explore the interplay of implicit and explicit attitudes on teaching behavior and examine the impact of either concordant or discriminant attitudes.

In summary, the ST-IAT represents an instrument that complements explicit measures in a way that helps more comprehensively assess preservice teachers' attitudes towards teaching and learning.

\section{Preservice Teachers' Attitude Development After Student Teaching}

When it comes to explicit attitude measures, both constructivist and transmissive attitudes decreased over time (from $T_{1}$ to $T_{2}$ ) in both groups. Implicit attitudes of both the lecture and the internship group remained stable throughout the semester and no significant differences between the mean values were found in the data (Table 1). An examination of the rank stability of the implicit and explicit measures may give an indication of the individual development of these preservice teachers. The testretest correlations of the explicit attitudes of the lecture group reveal significant correlations for both the construct of constructivism and the construct of transmission. The lecture groups' measures of implicit attitudes were also very stable in rank (Table 1). This indicates no individual attitude development in the lecture group, either on an implicit or on an explicit level.

As for the internship group, we found high test-retest correlations of the explicit measures of both constructivism and transmission (Table 1), which indicate no changes in rank from $T_{1}$ to $T_{2}$. In contrast to the lecture group, however, implicit pre- and post-measures of the internship group did not reveal significant correlations (Table 1). These changes in rank indicate inter-individual differences in the development of preservice teachers' implicit attitudes after student teaching. Thus, while some preservice teachers' attitudes remain stable, other preservice teachers' attitudes increase or decrease over the four-month-period of their internship. This finding complements results from Zaruba et al. (2018) who identified individual attitude development in teachers over the course of their internships but, unlike our results (Table 1), these were based on explicit measures and made use of different instruments.

In summary, preservice teachers' explicit attitudes changed over time both in the internship group and in the lecture group. Also, a semester of student teaching seems to have an effect on preservice teachers' implicit attitudes and one can assume that preservice teachers' attitudes develop individually. This does not, however, manifest itself in the mean values of implicit measures. One explanation for the changes on the explicit level for both groups over time could be that the students reflected on their attitudes during testing at the beginning of the semester and were then given time to consciously validate their views on constructivism and transmission, either during lectures and seminars or during their practical experiences., This may have led to a more differentiated view on teaching and learning. The individual development of implicit attitudes may be explained by the different experiences preservice teachers have at different schools during their placements and by the fact that every preservice teacher receives different guidance during their teaching placement, in the form of different mentors and different seminars. It is therefore plausible to assume that student teaching has a different effect on every preservice teacher. Indeed, Zaruba et al. (2019) found that preservice teachers reported differentiated experiences during student teaching, which led to a differentiated development of the preservice teachers' attitudes.

\section{Implications for Teacher Training}

We found changes in attitudes over time in both groups on the explicit level but no significant effect of time for the implicit attitudes. However, our results indicate that preservice teachers' attitudes on the implicit level, may develop individually for each preservice teacher after student teaching. This suggests that preservice teachers change their views on teaching when they are given the opportunity to reflect on it. Practical experiences in school even seem to have the potential to have an effect on implicit attitudes. In gaining practical experience, preservice teachers consciously and unconsciously validate their attitudes towards teaching and learning, whether it be by sitting in on classes, teaching by themselves, or by interacting with students (Richardson, 1996; Richardson, 2003; Fives et al., 2015).

This also raises the question of how teacher training can help preservice teachers develop and implement attitudes that serve as a basis for high-quality teaching that fosters student achievement. Dubberke et al. (2008) and Voss et al. (2013) showed that 
teachers' views on teaching influenced their teaching behavior and in turn, student achievement. In our study, we found that preservice teachers both strongly agree with the concept of transmission and constructivism on the explicit level and express positive attitudes towards them. Studies by Möller et al. (2006), as well as Staub and Stern (2002), indicate that constructivist views on teaching are associated with student achievement. On the other hand, a study by Kroesbergen (2004) shows that transmissive teaching strategies proved to be effective in teaching children with learning difficulties. Thus, preservice teachers should be given learning opportunities in which they can reflect on students' needs in order to realize adaptive teaching environments with both constructivist and transmissive teaching elements. Learning opportunities could include seminars in which preservice teachers reflect on their attitudes and plan lessons in accordance with their views on teaching and learning. In addition, preservice teachers should be encouraged to put these lessons into practice in the real world, and should be given the opportunity to reflect on these experiences, supported by professional guidance from trained mentors. Reflection and meaningful experiences can in turn help create new associative patterns (Gawronski and Bodenhausen, 2006), which cultivate and strengthen preservice teachers' attitudes.

\section{Limitations and Prospects}

Our findings are limited by the following factors, which should be taken into consideration in future research. First, we focused on preservice teachers who completed a semester of student teaching in Potsdam. Seeing as every university has different approaches to student teaching semesters, we cannot generalize our findings to other concepts for student teaching. In future studies, we would recommend including preservice teachers from different universities and from other countries with different student teaching concepts to see if our results can be replicated.

It would also be enlightening to have some indication of which elements of in-service teacher training account for these developments in students. Could, for instance, a specific reflection program carried out in seminars lead to stronger constructivist views on teaching (Decker et al., 2015) or is the "reality shock" (Voss und Kunter, 2020) so powerful that it interferes with this kind of reflection? Our study cannot explain why students develop in one way or another and it remains unclear exactly what role student teaching experiences have on these outcomes. With the help of, for instance, qualitative interview data, researchers could gain a clearer insight into the highly individual ways in which preservice teachers develop and the factors that influence this development. This would be especially fruitful if the results were considered together and were triangulated.

In our study, we only tested the ST-IAT transmission and constructivism with preservice teachers. In future studies, both tests should also be carried out with a sample of in-service teachers. In addition, it would be interesting to investigate the stabilities of different time intervals to see when a possible variance in rank (such as the variance we found in the internship group) shows up for the first time, and if this variance can be found in follow-up measures.

Future studies should aim to carefully select the stimuli for the implicit measures. An alternative way of choosing stimuli to the route we took could be to interview potential participants about their experiences with transmissive and constructivist teaching and to identify which keywords these participants use to describe these two approaches to teaching. These keywords could then serve as IAT stimuli. It cannot be ruled out that the stimulus words we chose carry positive or negative valences in themselves. Future studies could pretest stimuli for positive and negative valences independent of the target concept's context.

It would also be desirable to further validate the explicit measures by, for instance, considering if the participants' understanding of the items in the transmission and constructivism scale or of the ST-IAT stimuli are in accordance with their understanding of constructivism and transmission as a whole. Moreover, future studies could analyze in how far our operationalization of constructivism and transmission can be defined from other related constructs, such as mastery- and performance-based instruction. Researchers could also investigate the potential effects of preservice teachers' attitudes on student achievement. In addition to that, our study is based on the assumption that preservice teachers' might be prone to socially biased response behavior when asked about their attitudes towards constructivism and transmission. Although this assumption is based on the view of constructivism being more desirable than transmission (e.g., Mayer, 2004), there is no empirical data showing that it results in strategic responding. This is why future studies should investigate this question further.

\section{CONCLUSION}

In this study, we were able to successfully measure both implicit and explicit attitudes of preservice teachers on teaching and learning. The results illuminate preservice teachers' attitudes towards the end of their training to become teachers. Preservice teachers agreed on the explicit level with both the concept of transmission and of constructivism at the end of their master's studies, while exhibiting positive implicit constructivist and transmissive attitudes. The data also indicated that, after a semester of student teaching, preservice teachers' implicit attitudes towards constructivism and transmission may have developed individually and differentially.

\section{DATA AVAILABILITY STATEMENT}

The data sets presented in this article are not readily available. When the data was obtained, the participants were informed that the data will only be used for the purpose of this study and not, in any form, be available to third parties. The data set can therefore not be shared by the corresponding author. 


\section{ETHICS STATEMENT}

Ethical review and approval was not required for the study on human participants in accordance with the local legislation and institutional requirements. The participants provided their written informed consent to participate in this study.

\section{AUTHOR CONTRIBUTIONS}

Nicole Zaruba conceptualized the study, was responsible for test creation, the pretest, organizing data collection and data analysis; Nicole Zaruba wrote the manuscript. Andrea Westphal provided expertise on the study conceptualization and data analysis. Andrea Westphal, Miriam Vock and Franziska Gutmann provided support for the interpretation of the study, assisted with the writing of the manuscript and revised it critically. All authors approved of the final manuscript version.

\section{REFERENCES}

Amt für Statistik Berlin-Brandenburg (2017). Statistischer Bericht - Lehrkräfte an allgemeinbildenden Schulen im Land Brandenburg Schuljahr 2016/2017 [Statistical report: Teachers on general schools in the federal state of Brandenburg]. Available at: https://www.statistik-berlin-brandenburg.de/ publikationen/stat_berichte/2017/SB_B01-02-00_2016j01_BB.pdf.

Bar-Anan, Y., and Nosek, B. A. (2014). A comparative investigation of seven indirect attitude measures. Behav. Res. 46 (3), 668-688. doi:10.3758/s13428-013-0410-6

Baumert, J., Blum, W., Brunner, M., Dubberke, T., Jordan, A., Klusmann, U., et al. (2009). Professionswissen von Lehrkräften, kognitiv aktivierender Mathematikunterricht und die Entwicklung von mathematischer Kompetenz (COACTIV): Dokumentation der Erhebungsinstrumente [Teachers' professional knowledge, cognitively activating math lessons and the development of mathematical competence (COACTIV): Documentation of the research tools]. Berlin, Germany: Max-Planck-Institut für Bildungsforschung.

Baumert, J., and Kunter, M. (2013). "The COACTIV model of teachers' professional competence," in Cognitive activation in the mathematics classroom and professional competence of teachers: Results from the COACTIV project. Editors M. Kunter, J. Baumert, W. Blum, U. Klusmann, S. Krauss, and M. Neubrand (Boston, MA: Springer), 25-48.

Bluemke, M., and Friese, M. (2008). Reliability and validity of the single-target IAT (ST-IAT): Assessing automatic affect towards multiple attitude objects. Eur. J. Soc. Psychol. 38 (6), 977-997. doi:10.1002/ejsp.487

Buehl, M. M., and Beck, J. S. (2015). "The relationship between teachers' beliefs and teachers' practices," in International handbook of research on teachers' beliefs. Editors H. Fives and M. Gregoire Gill (London, United Kingdom: Routledge), 66-84.

Chen, J. A., Morris, D. B., and Mansour, N. (2015). "Science teachers' beliefs: Perceptions of efficacy and the nature of scientific knowledge and knowing," in International handbook of research on teachers' beliefs. Editors H. Fives and M. Gregoire Gill (London, United Kingdom: Routledge), 370-386.

De Houwer, J. (2006). "What are implicit measures and why are we using them?," in Handbook of implicit cognition and addiction. Editors R. W. Wiers and A. W. Stacy (Thousand Oaks, CA: Sage), 11-28.

Decker, A.-T., Kunter, M., and Voss, T. (2015). The relationship between quality of discourse during teacher induction classes and beginning teachers' beliefs. Eur. J. Psychol. Educ. 30 (1), 41-61. doi:10.1007/s10212-014-0227-4

Dicke, T., Holzberger, D., Kunina-Habenicht, O., Linninger, C., Schulze-Stocker, F., Seidel, T., et al. (2016). "Doppelter Praxisschock" auf dem Weg ins Lehramt? Verlauf und potenzielle Einflussfaktoren emotionaler Erschöpfung während des Vorbereitungsdienstes und nach dem Berufseintritt. Psychol. Erziehung Unterricht. 63 (4), 244-257. doi:10.2378/peu2016.art20d

\section{FUNDING}

This work was supported by the Federal Ministry of Education and Research (grant number 01JA1516). The publication of this article was supported by the Potsdam Graduate School of the University of Potsdam, Germany (no grant number). The authors are responsible for the content of this publication. The funding sources were not involved in the study design, the collection, analysis, and interpretation of data, in the writing of the report or the decision to submit the article for publication.

\section{ACKNOWLEDGMENTS}

We would like to thank the participants, as well as Laura Engler, Clara Josepha Hoferichter, Max Borchelt and Saskia Schmat for their help during data collection and preparation. We would also like to thank Ben Fergusson and Amy J. Walker for their editorial assistance with this article.

Dubberke, T., Kunter, M., McElvany, N., Brunner, M., and Baumert, J. (2008). Lerntheoretische Überzeugungen von Mathematiklehrkräften. Z. für Pädagogische Psychol. 22 (3), 193-206. doi:10.1024/1010-0652.22.34.193

Duffin, L. C., French, B. F., and Patrick, H. (2012). The teachers' sense of efficacy scale: Confirming the factor structure with beginning pre-service teachers. Teach. Teach. Edu. 28 (6), 827-834. doi:10.1016/j.tate.2012.03.004

Eagly, A. H., and Chaiken, S. (1998). "Attitude structure and function," in The handbook of social psychology. Editors D. T. Gilbert, S. T. Fiske, and G. Lindzey (New York, NY: McGraw-Hill), 269-322.

Egloff, B., Schwerdtfeger, A., and Schmukle, S. C. (2005). Temporal stability of the implicit association test-anxiety. J. Personal. Assess. 84 (1), 82-88. doi:10.1207/ s15327752jpa8401_14

Fazio, R. H., Jackson, J. R., Dunton, B. C., and Williams, C. J. (1995). Variability in automatic activation as an unobtrusive measure of racial attitudes: A bona fide pipeline? J. Personal. Soc. Psychol. 69 (6), 1013-1027. doi:10.1037/0022-3514.69. 6.1013

Fazio, R. H., and Olson, M. A. (2003). Implicit measures in social cognition research: Their meaning and use. Annu. Rev. Psychol. 54 (1), 297-327. doi:10. 1146/annurev.psych.54.101601.145225

Fiedler, K., and Bluemke, M. (2005). Faking the IAT: Aided and unaided response control on the implicit association tests. Basic Appl. Soc. Psychol. 27 (4), 307-316. doi:10.1207/s15324834basp2704_3

Fives, H., and Buehl, M. M. (2012). "Spring cleaning for the "messy" construct of teachers' beliefs: What are they? Which have been examined? What can they tell us?," in APA educational psychology handbook. Editors K. R. Harris, S. Graham, T. Urdan, S. Graham, J. M. Royer, and M. Zeidner (Washington, DC: American Psychological Association), 471-499.

Fives, H., Lacatena, N., and Gerard, L. (2015). "Teachers' beliefs about teaching (and learning)," in International handbook of research on teachers' beliefs. Editors H. Fives and M. Gregoire Gill (London, United Kingdom: Routledge), 249-265.

Gawronski, B., and Bodenhausen, G. V. (2006). Associative and propositional processes in evaluation: An integrative review of implicit and explicit attitude change. Psychol. Bull. 132 (5), 692-731. doi:10.1037/0033-2909.132.5.692

Greenwald, A. G., McGhee, D. E., and Schwartz, J. L. K. (1998). Measuring individual differences in implicit cognition: the implicit association test. J. Personal. Soc. Psychol. 74 (6), 1464-1480. doi:10.1037/0022-3514.74.6.1464

Greenwald, A. G., Nosek, B. A., and Banaji, M. R. (2003). Understanding and using the implicit association test: I. An improved scoring algorithm. J. Personal. Soc. Psychol. 85 (2), 197-216. doi:10.1037/0022-3514.85.2.197

Greenwald, A. G., Poehlman, T. A., Uhlmann, E. L., and Banaji, M. R. (2009). Understanding and using the implicit association test: III. Meta-analysis of predictive validity. J. Personal. Soc. Psychol. 97 (1), 17-41. doi:10.1037/a0015575 Gregoire Gill, M., and Hardin, C. (2015). "A "hot” mess: Unpacking the relation between teachers' beliefs and emotions," in International handbook of research 
on teachers' beliefs. Editors H. Fives and M. Gregoire Gill (London, United Kingdom: Routledge), 230-246.

Gregoire, M. (2003). Is it a challenge or a threat? A dual-process model of teachers' cognition and appraisal processes during conceptual change. Educ. Psychol. Rev. 15 (2), 147-179. doi:10.1023/A:1023477131081

Hermans, R., van Braak, J., and Van Keer, H. (2008). Development of the beliefs about primary education scale: Distinguishing a developmental and transmissive dimension. Teach. Teach. Edu. 24 (1), 127-139. doi:10.1016/j.tate.2006.11.007

Juvova, A., Chudy, S., Neumeister, P., Plischke, J., and Kvintova, J. (2015). Reflection of constructivist theories in current educational practice. Univers. J. Educ. Res. 3 (5), 345-349. doi:10.13189/ujer.2015.030506

Karpinski, A., and Steinman, R. B. (2006). The single category implicit association test as a measure of implicit social cognition. J. Personal. Soc. Psychol. 91 (1), 16-32. doi:10.1037/0022-3514.91.1.16

Kim, H., and Cho, Y. (2014). Pre-service teachers' motivation, sense of teaching efficacy, and expectation of reality shock. Asia-pacific J. Teach. Edu. 42 (1), 67-81. doi:10.1080/1359866X.2013.85599

Kroesbergen, E. H. (2004). Effectiveness of explicit and constructivist mathematics instruction for low-achieving students in the Netherlands. Elem. Sch. J. 104 (3), 233-251. doi:10.1086/499751

Krosnick, J. A., Judd, C. M., and Wittenbrink, B. (2005). "The measurement of attitudes," in The handbook of attitudes. Editors D. Albarracín, B. T. Johnson, and M. P. Zanna (New York, NY: Taylor \& Francis), 21-76.

Lautenbach, F., and Antoniewicz, F. (2018). Ambivalent implicit attitudes towards inclusion in preservice PE teachers: The need for assessing both implicit and explicit attitudes towards inclusion. Teach. Teach. Edu. 72, 24-32. doi:10.1016/j. tate.2018.01.003

Leuchter, M., Pauli, C., Reusser, K., and Lipowsky, F. (2006). Unterrichtsbezogene Überzeugungen und handlungsleitende Kognitionen von Lehrpersonen. $Z$ Erziehwiss. 9 (4), 562-579. doi:10.1007/s11618-006-0168-z

Levin, B. B. (2015). "The development of teachers' beliefs," in International handbook of research on teacher's beliefs. Editors H. Fives and M. Gregoire Gill (London, United Kingdom: Routledge), 48-65.

Lortie, D. C. (1975). Schoolteacher: A sociological study. Chicago, IL: The University of Chicago Press .

Lüke, T., and Grosche, M. (2018). Implicitly measuring attitudes towards inclusive education: a new attitude test based on single-target implicit associations. Eur. J. Spec. Needs Edu. 33, 427-436. doi:10.1080/08856257.2017.1334432

Lüke, T., and Grosche, M. (2017). What do I think about inclusive education? It depends on who is asking. Experimental evidence for a social desirability bias in attitudes towards inclusion. Int. J. Inclusive Edu. 22 (1), 38-53. doi:10.1080/ 13603116.2017.1348548

Mayer, R. E. (2004). Should there be a three-strikes rule against pure discovery learning?. Am. Psychol. 59 (1), 14-19. doi:10.1037/0003-066X.59.1.14

Mikeska, J. N., Kurzum, C., Steinberg, J. H., and Xu, J. (2018). Report ETS PR-1820. Assessing elementary teachers' content knowledge for teaching science for the ETS educator series: pilot results. 1-30. doi:10.1002/ets2.12207

Möller, K., Hardy, I., Jonen, A., Kleickmann, T., and Blumberg, E. (2006). "Naturwissenschaften in der Primarstufe. zur Förderung konzeptuellen Verständnisses durch Unterricht und zur Wirksamkeit von Lehrerfortbildungen [Science in elementary school. On fostering conceptual understanding through instruction and the effectiveness of further training for teachers]," in Untersuchungen zur Bildungsqualität von Schule. Abschlussbericht des DFG-Schwerpunktprogramms biQua. Editors M. Prenzel and L. AllolioNäcke (Münster, Germany: Waxmann), 161-193.

Nettle, E. B. (1998). Stability and change in the beliefs of student teachers during practice teaching. Teach. Teach. Edu. 14 (2), 193-204. doi:10.1016/S0742051X(97)00031-010.1016/s0742-051x(97)00031-0

Nosek, B. A. (2007). Implicit-explicit relations. Curr. Dir. Psychol. Sci. 16 (2), 65-69. doi:10.1111/j.1467-8721.2007.00477.x

Pajares, M. F. (1992). Teachers' beliefs and educational research: Cleaning up a messy Construct. Rev. Educ. Res. 62 (3), 307-332. doi:10.3102/00346543062003307

Perrot, E. (1982). Effective teaching: A practical guide to improving your teaching. New York, NY: Longman.

Perry, B., Tracey, D., and Howard, P. (1999). Head mathematics teachers' beliefs about the learning and teaching of mathematics. Math. Ed. Res. J. 11 (1), 39-53. doi:10.1007/BF03217349
Pit-Ten Cate, I. M., and Glock, S. (2019). Teachers' implicit attitudes toward students from different social groups: a meta-analysis. Front. Psychol. 10, 28321-28418. doi:10.3389/fpsyg.2019.02832

Preckel, F., Baudson, T. G., Krolak-Schwerdt, S., and Glock, S. (2015). Gifted and maladjusted? Implicit attitudes and automatic associations related to gifted children. Am. Educ. Res. J. 52 (6), 1160-1184. doi:10.3102/0002831215596413

Richardson, V. (1996). "The role of attitudes and beliefs in learning to teach," in In Handbook of research on teacher education. Editor J. Sikula (New York, NY: Macmillan), 102-119.

Richardson, V. (2003). "Preservice teachers' beliefs," in Teacher beliefs and classroom performance: the impact of teacher education. Editors J. Raths and A. C. McAninch (Greenwich, CT: Information Age Publishing), 1-22.

Rimm-Kaufman, S. E., Storm, M. D., Sawyer, B. E., Pianta, R. C., and LaParo, K. M. (2006). The teacher belief Q-sort: A measure of teachers' priorities in relation to disciplinary practices, teaching practices, and beliefs about children. J. Sch. Psychol. 44, 141-165. doi:10.1016/j.jsp.2006.01.003

Rokeach, M. (1968). Beliefs, attitudes, and values: a theory of organization and change. San Francisco, CA: Jossey-Bass.

Rothland, M., and Boecker, S. K. (2015). Viel hilft viel? Forschungsbefunde und -perspektiven zum Praxissemester in der Lehrerbildung [A lot helps a lot? Research findings and perspectives regarding student teaching]. Lehrerbildung auf dem Prüfstand 8 (2), 112-134.

Schlichter, N. (2012). Lehrerüberzeugungen zum Lehren und Lernen [Teachers beliefs about teaching and learning]. Dissertation. Göttingen, Germany: GeorgAugust-Universität Göttingen.

Schraw, G., and Olafson, L. (2015). "Assessing teacher's beliefs. Challenges and solutions," in International handbook of research on teachers' beliefs. Editors H. Fives and M. Gregoire Gill (London, United Kingdom: Routledge), 87-105.

Seidel, T., and Meyer, L. (2003). "Skalendokumentation Lehrerfragebogen [Documentation of the scales for the teacher survey]," in Technischer Bericht zur Videostudie, Lehr-Lern-Prozesse im Physikunterricht. Editors T. Seidel, M. Prenzel, R. Duit, and M. Lehrke (Kiel, Germany: LeibnizInstitut für die Pädagogik der Naturwissenschaften (IPN)). 241-274.

Seifried, S., and Heyl, V. (2016). Konstruktion und Validierung eines Einstellungsfragebogens zu Inklusion für Lehrkräfte (EFI-L) [Construction and validation of a questionnaire on attitudes towards inclusion for teachers]. Empirische Sonderpädagogik. 1, 22-35.

Skott, J. (2015). "The promises, problems, and prospects of research on teachers' beliefs," in International handbook of research on teachers' beliefs. Editors H. Fives and M. Gregoire Gill (London, United Kingdom: Routledge), 13-30.

Snider, V. E., and Roehl, R. (2007). Teachers' beliefs about pedagogy and related issues. Psychol. Schs. 44 (8), 873-886. doi:10.1002/pits.20272

Staub, F. C., and Stern, E. (2002). The nature of teachers' pedagogical content beliefs matters for students' achievement gains: Quasi-experimental evidence from elementary mathematics. J. Educ. Psychol. 94 (2), 344-355. doi:10.1037/ 0022-0663.94.2.344

Strack, F., and Deutsch, R. (2004). Reflective and impulsive determinants of social behavior. Pers Soc. Psychol. Rev. 8 (3), 220-247. doi:10.1207/s15327957pspr0803_1

Svegliato, J. (2017). Open-SR [Computer program]. Available at: https://github. com/justinsvegliato/opensr.

Terhart, E. (2003). Constructivism and teaching: a new paradigm in general didactics? J. Curriculum Stud. 35 (1), 25-44. doi:10.1080/00220270210163653

Voss, T., Kleickmann, T., Kunter, M., and Hachfeld, A. (2013). "Mathematics teachers' beliefs," in Cognitive activation in the mathematics classroom and professional competence of teachers. Editors M. Kunter, J. Baumert, W. Blum, U. Klusmann, S. Krauss, and M. Neubrand (Boston, MA: Springer), 249-271.

Voss, T., and Kunter, M. (2020). "Reality shock" of beginning teachers? Changes in teacher candidates' emotional exhaustion and constructivist-oriented beliefs. J. Teach. Edu. 71 (3), 292-306. doi:10.1177/0022487119839700

Wilcox-Herzog, A. S., Ward, S. L., Wong, E. H., and McLaren, M. S. (2015). "Preschool teachers' ideas about how children learn best. An examination of beliefs about the principles of developmentally appropriate practice," in International handbook of research on teachers beliefs. Editors H. Fives and M. Gregoire Gill (London, United Kingdom: Routledge), 421-435.

Wittenbrink, B., and Schwarz, N. (2007). "Introduction," in Implicit measures of attitudes. Editors B. Wittenbrink and N. Schwarz (New York, NY: Guilford), 1-13. 
Zaruba, N., Gronostaj, A., Ahlgrimm, F., and Vock, M. (2019). "Unter welchen Bedingungen entwickeln sich Überzeugungen im Praxissemester? Eine Interviewstudie [Under which circumstances do preservice teachers' beliefs develop during a semester of student teaching? A qualitative study]," in Lehrer. Bildung. Gestalten. Beiträge zur empirischen Bildungsforschung in der Lehrerbildung. Editors T. Ehmke, P. Kuhl, and M. Pietsch (Weinheim und Basel: Beltz Juventa), 20-32.

Zaruba, N., Gronostaj, A., Kretschmann, J., and Vock, M. (2018). "Mehr Schüler*innenorientierung oder Praxisschock? Wie sich unterschiedliche Überzeugungen von Lehrkräften während des Praxissemesters verändern [More student orientation or reality shock? How different beliefs of teachers change after a semester of student teaching]," in Empirische Bildungsforschung im Kontext von Schule und Lehrer ${ }^{*}$ innenbildung. Editors A. Krüger, F. Radisch, A. S. Willems, T. Häcker, and M. Walm (Bad Heilbrunn, Germany: Julius Klinkhardt), 223-235.
Zeichner, K. (2012). The turn once again toward practice-based teacher education. J. Teach. Edu. 63 (5), 376-382. doi:10.1177/0022487112445789

Conflict of Interest: The authors declare that the research was conducted in the absence of any commercial or financial relationships that could be construed as a potential conflict of interest.

Copyright (c) 2021 Zaruba, Westphal, Gutmann and Vock. This is an open-access article distributed under the terms of the Creative Commons Attribution License (CC $B Y$ ). The use, distribution or reproduction in other forums is permitted, provided the original author(s) and the copyright owner(s) are credited and that the original publication in this journal is cited, in accordance with accepted academic practice. No use, distribution or reproduction is permitted which does not comply with these terms. 